\title{
PAPILOMAVIRUS Y CÁNCER DE CÉRVIX
}

\section{PAPILOMAVIIRUIS IN CERVICAL CARCINOMA}

\author{
Hernán Cortés Yepes, M.D.*
}

Recibido: octubre 18/2002 - Revisado: noviembre 14/2002 - Aceptado: diciembre 10/2002

\section{RESUMEN}

La infección por el papilomavirus humano (pvh), es la enfermedad de transmisión sexual mas común en el mundo. El pvh es causa necesaria para el desarrollo de cáncer de cérvix, pero no es suficiente ya que otros factores están involucrados en la progresión de infección a cáncer. El pvh pertenece a la familia Papovaviridae y es un virus DNA, se clasifica en cutáneo y mucoso. Se discute la evidencia epidemiológica de la causalidad entre el PVH y el cáncer de cérvix y los mecanismos de oncogénesis del virus.

Palabras clave: papilomavirus, cáncer de cérvix, epidemiología, patogénesis, proteínas virales, vacunación.

\section{SUMMARY}

The human papillomavirus (HPV) infection is the most common sexually transmitted disease in the world. The HPV is a necessary cause for the cervical cancer development, but is not enough, because other factors are involved in the infection

Ginecólogo y Obstetra, docente Departamento de Ginecología y Obstetricia. Universidad de Antioquia. Medellín-Colombia. to cancer progression. The HPV belongs to the Papovaviridae family, it is a DNA virus and is classified as a cutaneous and mucous virus. It is discussed the epidemiological evidence in the chance between HPV and cervical cancer and the oncogenic mechanisms of the virus.

Key words: papillomavirus, cervical cancer, epidemiology, pathogenesis, viral proteins, vaccination.

\section{EPIDEMIOLOGÍA DEL PVH}

La infección por el papilomavirus humano (PVH), es la enfermedad de transmisión sexual mas común en el mundo; al menos el 60\% de las mujeres con vida sexual activa menores de 35 años han tenido infección genital por PVH.

La prevalencia mundial de esta infección de transmisión sexual (ITS), (aunque se describen otras formas de transmisión) oscila entre el 5\% y el 40\%, dependiendo del tipo de población estudiada y los métodos de detección (tabla 1). ${ }^{1}$

Es de anotar que los estudios realizados en Colombia donde se observa uno de los porcentajes mas bajos se realizó en 1995, utilizando técnicas menos sensibles que las que se usan actualmente. 


\begin{tabular}{cc}
\multicolumn{2}{c}{ Tabla 1. Prevalencia de PVH } \\
\multicolumn{1}{c}{ País } & $\%$ \\
\hline Estados Unidos & $10-55$ \\
\hline México & 44 \\
\hline Colombia & 34 \\
\hline Argentina & 32 \\
\hline
\end{tabular}

La prevalencia de PVH también varía con la edad, siendo esta mayor en las pacientes menores de 25 años, donde alcanza hasta un 60\% en comparación con la prevalencia en mayores de 34 años donde es aproximadamente del $25 \% .^{2}$

\section{EPIDEMIOLOGÍA DEL CANCER DE CÉRVIX}

El cáncer del cuello uterino es el segundo cáncer en las mujeres luego del cáncer de mama a nivel mundial, correspondiendo al 15\% de ellos, su pico de incidencia es a los 51 años y es la primera causa de mortalidad por cáncer ginecológico.

Anualmente se espera la aparición de 500000 casos nuevos y 200000 muertes por esta causa. La mayor incidencia y mortalidad de esta patología se presenta en los países en vías de desarrollo donde los programas de detección precoz no han sido exitosos, por ejemplo la incidencia del cáncer de cérvix en Israel es de 3 x 100 000, mientras que en Brasil es de 83,2 x $100000 .^{3}$

La situación en Colombia es similar a la de los países en desarrollo, siendo este la principal causa de cáncer y el primero en las mujeres (16\% de todos), con una incidencia según las regiones que varía de 44 a 88 x 100 000, con un pico de incidencia mas temprano de 40 a 50 años y es la principal causa de muerte en las mujeres de 35 a 44 años. ${ }^{4}$

\section{CAUSALIDAD PVH Y CÁNCER DE CÉRVIX}

Se ha demostrado que el PVH es una causa necesaria para el desarrollo del cáncer de cérvix, pero no es suficiente, ya que solo una pequeña proporción de las mujeres infectadas por aquel desarrollan el cáncer, indicando que otros factores están involucrados en la progresión de la infección al cáncer.

Varios estudios epidemiológicos avalan este relación; Muñoz y cols. encontraron $\mathrm{PVH}$ en el 99,7\% de los casos de cáncer de cérvix, ${ }^{1}$ otros estudios de casos y controles realizados en 13 países por esta misma autora demostraron factor de asociación (odds ratio - OR) de 70 con un IC 95\% 57 a 88 , que es mayor que el OR entre cigarrillo y cáncer de pulmón, en Colombia el OR fue de 18 y en Filipinas de 200, se encontró además que esta relación era similar tanto para el carcinoma escamocelular, como para el adenocarcinoma. ${ }^{1}$

Como ya se mencionó otros factores están implicados en la progresión de esta infección, a saber: ${ }^{3}$

Multiparidad

Uso prolongado de anticonceptivos orales Cigarrillo

Inmunosupresión

Otras ITS (Chlamydia trachomatis y herpes virus 2)

Factores sexuales, entre otros

Multiparidad: se demostró que la multiparidad aumenta el riesgo de carcinoma escamocelular de cérvix entre las mujeres positivas para $\mathrm{PVH}$, con un OR de 3,8 cuando la mujer ha tenido 7 ó más embarazos a término. ${ }^{5}$

Uso prolongado de anticonceptivos: el riesgo de cáncer de cérvix es casi tres veces mayor en las mujeres que han usado anticonceptivos por 5 a 9 años (OR 2,82) en comparación con aquellas que nunca los han usado o lo han hecho por un tiempo menor; este riesgo es de 4 cuando el uso es mayor de 10 años. (OR 4,03). ${ }^{6}$

Cigarrillo e inmunosupresión: se ha demostrado que los productos de desecho y metabolitos del cigarrillo se encuentran en las secreciones cervicales y que estos inhiben la presentación de 
antígenos por parte de las células de Langerhans, evitando posiblemente el reconocimiento del PVH por el sistema inmune, igualmente en las pacientes con VIH/sida se ha encontrado una mayor probabilidad de desarrollar el cáncer y un menor tiempo de progresión. ${ }^{3}$

Factores sexuales: al parecer no son un riesgo como tal, si no que exponen a la mujer al PVH (principal factor de riesgo), se han mencionado los siguientes: inicio temprano de relaciones sexuales, promiscuidad, entre otros.

\section{PATOGÉNESIS DEL PVH}

El papilomavirus humano $(\mathrm{PVH})$, pertenece a la familia Papovaviridae. Es un virus de estructura icosahédrica de 72 capsómeras, sin cápsula, posee un DNA circular de doble cadena de aproximadamente $8 \mathrm{~kb}$; se reconocen 86 tipos los cuáles se establecen por diferencias en su DNA de al menos el $90 \%$.

Dependiendo de su afinidad por los tejidos se clasifican en cutáneos y mucosos.

El genoma del PVH (figura 1) está constituido por 7200 a 8000 pares de bases y se divide en tres regiones:

La Organización Mundial de la Salud (OMS) y la Agencia Internacional para la Investigación en Cáncer (IARC) clasifican el PVH según el riesgo de carcinogenicidad en alto y bajo riesgo tabla 2). ${ }^{7,8}$

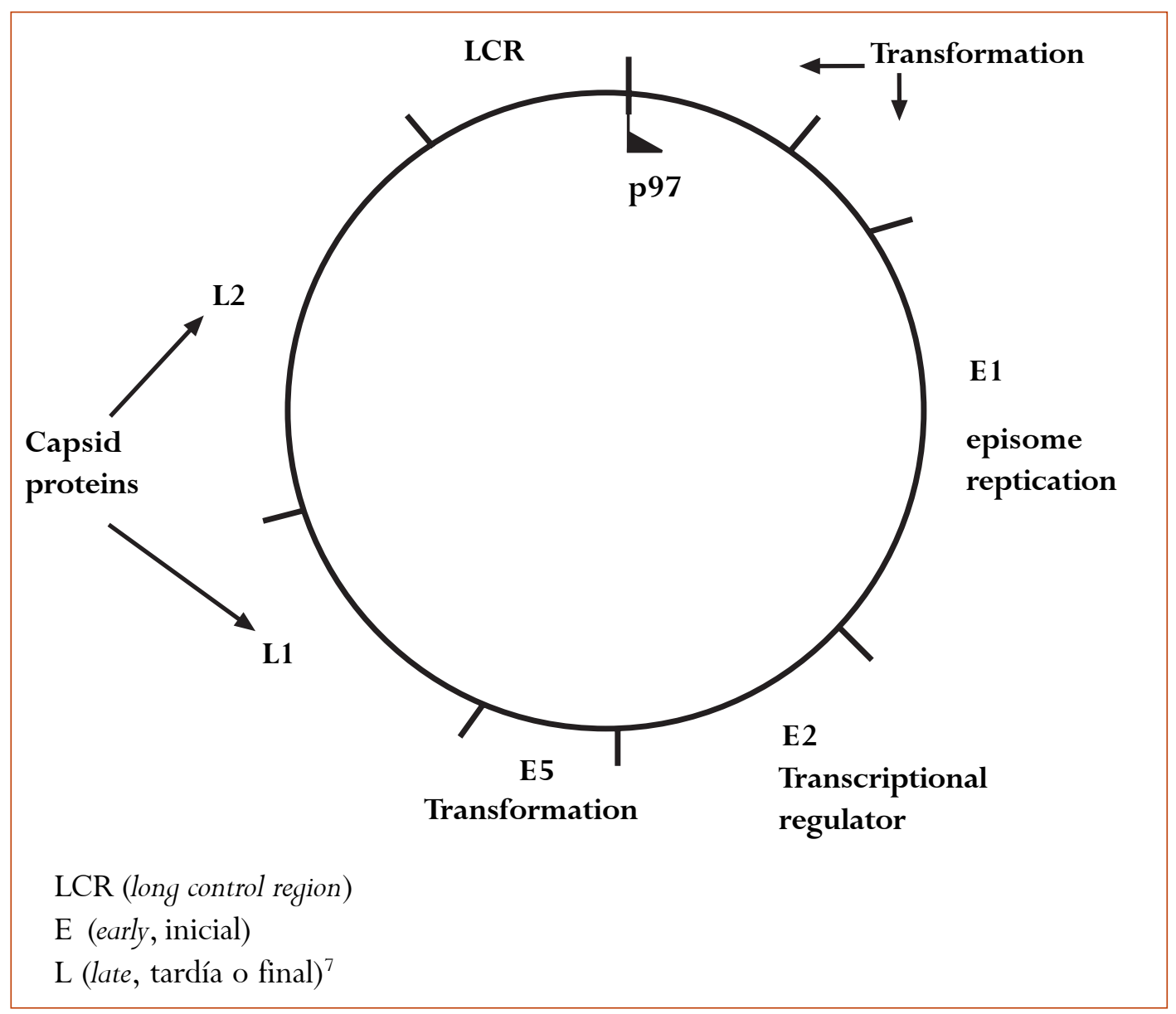

Figura 1. Genoma del PVH. 
Tabla 2. Carcinogenicidad del PVH

Bajo riesgo $6,11,40,42-45,53-55,57,59,61$, $67,69,71,74,82$.

Alto riesgo $16,18,31-35,51-52,56,58,61,66$, $68,70,73$.

\section{HISTORIA NATURAL DE LA INFECCIÓN POR PVH}

Poco se sabe de la historia natural de esta infección, pero la mayoría de los estudios han demostrado que esta es una enfermedad transitoria y la persistencia del mismo tipo de PVH es rara, en la mayoría de las mujeres infectadas (95\%), el DNA del virus se vuelve indetectable en 2 años y en general la infección dura aproximadamente 8 meses. ${ }^{9}$

La persistencia de la infección se presenta con los $\mathrm{PVH}$ de alto riesgo y se relaciona con el desarrollo de cáncer, se conocen además algunos factores de riesgo de persistencia:

- Mayor edad

- Uso de anticonceptivos por 2 años o más

- Promiscuidad

No se ha encontrado relación entre el riesgo de persistencia y la edad de inicio de las relaciones sexuales, uso o no de preservativo, otras ITS y el uso de cigarrillo. ${ }^{9}$

\section{MECANISMOS DE ONCOGÉNESIS DEL PVH}

\section{Replicación}

El virus ingresa al epitelio a través de microlesiones e infecta las células del epitelio basal y allí se mantienen 50 a 100 copias de virus por célula; cuando se presenta la división celular una célula empieza a migrar hacia la superficie e inicia su proceso de diferenciación, lo cual es un problema para el virus que requiere de toda la maquinaria replicativa de la célula para la síntesis de su DNA; sin embargo, el virus requiere de algún nivel de diferenciación ya que el promoter que regula la síntesis de la cápside solo se activa en células parcialmente diferenciadas.

Por lo tanto el virus debe alterar la progresión de la fase $\mathrm{G} 1$ a la $\mathrm{S}$ para realizar su replicación en la capa granular y la síntesis de la cápside y amplificación de su DNA cerca de la capa córnea. ${ }^{7}$

A continuación se hará una breve descripción de los mecanismos del virus para lograr un ambiente celular adecuado para su replicación.

\section{PROTEÍNA E6}

Es una proteína de 151 aminoácidos, con 2 dominios de zinc que se expresa de manera temprana en el curso de la infección.

Se sabe que esta proteína es capaz de inmortalizar las células epiteliales de mamíferos, y los queratinocitos humanos (HFK) en presencia de la proteína E7. ${ }^{10}$

Funciones de la proteína E6:

- Aumenta la vida celular, por activación de la telomerasa.

- Bloquea la apoptosis, por degradación y retención de la p53.

- Alteración en la transcripción de genes, principalmente p300.

- Interacción con otras proteínas (E6BP, c-myc, $\mathrm{N}$-myc, hDLG, entre otras).

\section{PROTEÍNA E7}

Es una proteína nuclear de 98 aminoácidos con tres dominios, CR1, CR2 y CR3, que interactúa con varias proteínas que regulan el crecimiento celular, también se asocia con proteínas de la familia de proteínas supresoras del retinoblastoma $(\mathrm{Rb})$, el complejo histona-deacetilasa, factores de 
transcripción (AP-1), ciclinas, ciclinas dependientes de cinasas (cdks) e inhibidores de cdks, estas asociaciones contribuyen a la capacidad de la E7 de inducir la proliferación celular y los procesos de inmortalización y transformación.

\section{PROTEÍNA E5}

Proteína de 84 aminoácidos, hidrofóbica y de membrana, que se encuentra principalmente en el retículo endoplásmico, el aparato de Golgi y la membrana citoplasmática; tiene la capacidad de transformar células de mamíferos.

Entre sus funciones están:

- Estimular factores de crecimiento e inhibir su recaptación (EGFR - PDGFR)

- Inhibir la ATPasa, para aumentar el número de receptores del retículo endoplásmico.

La proteína E5 no inmortaliza los queratinocitos (HFK), pero aumenta la vida de las células, además juega un papel importante en el proceso de inmortalización por parte de las proteínas E6 y E7; (cuando se altera la proteína E5 del PVH 16 se disminuye la capacidad de inmortalización de este hasta un $10 \%){ }^{11}$

\section{PROTEÍNAS E1 - E2}

Estas son esenciales en el proceso de replicación celular, controlando el número de copias del virus, al unirse aumentan su afinidad por el DNA; su función depende en gran medida del estado de diferenciación celular y por esto sus mecanismos de función y transcripción no han sido claramente elucidados.

\section{VACUINACIÓN}

El desarrollo de vacunas contra el PVH es muy importante, debido al bajo impacto de los programas de detección temprana en los países en desarrollo, donde la mortalidad por cáncer de cérvix es un problema de salud pública y al alto costo de estos programas en los países desarrollados (solo en Estados Unidos se gastan mas de 5 billones de dólares al año).

Están en estudio dos tipos de vacunas: la terapéutica y la profiláctica.

Vacuna terapéutica: busca inducir una respuesta citotóxica en la célula $\mathrm{T}$, por medio de la presentación del antígeno al complejo mayor de histocompatibilidad HLA 1, se basa en las proteínas E6 y E7. Se busca tratar la célula. ${ }^{8}$

Vacuna profiláctica: busca generar anticuerpos en las personas que no han tenido exposición al PVH, se basan en las proteínas L1 y L2, usando como vector proteínas similares al virus (VLP). ${ }^{8,12}$ Actualmente se están desarrollando estudios de fase III, con resultados preliminares muy alentadores.

\section{BIBLIOGRAFÍA}

1. Muñoz, N. Human Papillomavirus and cancer: the epidemiological evidence. Journal of Clinical Virology 2000; 19: 1-5.

2. Koutsky L. Epidemiology of genital human papillomavirus infection. Am J Med 1997; 102(5A): 2-9.

3. Berek JS. Cervical cancer. En: Berek JS., Hacker NF. Practical Gynecology Oncology. 3th edition. Lippincott Williams \& Wilkins 2000. pp 180-203.

4. Instituto Nacional de Cancerología. Epidemiología cáncer en Colombia durante el año 1999 - 2000. Bogotá 2000. (Documento web: www.incancerologia.gov.co).

5. Muñoz N, Franceschi S, Bosetti C et al. Role of parity and human papillomavirus in cervical cancer: the IARC multicentric case-control study. Lancet 2002; 359: 1093-101.

6. Moreno V, Bosch FX, Muñoz N, et al. Effect of oral contraceptives on risk of cervical cancer in women with human papillomavirus infection: the IARC multicentric case-control study. Lancet 2002; 359: 1085-192. 
7. McMurray HR, Nguyen D, Westbrook TF, Mcance DJ. Biology of human papillomaviruses. Viruses and Cancer 2001; 82: 15-33.

8. Unger E, Duarte-Franco, E. Human papillomaviruses. Into the new millennium. Obstet Gynecol Clinics 2001; 28(4): 653-6.

9. Tortolero-Luna G. Epidemiology of genital human papillomavirus. Hematol Oncol Clin of NA 1999; 13(1): 245-57.
10. Kiyono T, Foster SA, Koop JL, et al. Telomerasa activity are required to inmortalize human ephitelial cells. Nature 1998; 396: 84-88.

11. Straight SW, Herman B, McCance DJ. The E5 oncoprotein of human papillomavirus type 16 inhibits the acidification of endosomes in human keratinocytes. J Virol 1995; 69: 3185-3192.

12. Hildesheim, A. HPV prophylactic vaccines. Handbook: Pathogenesis of human oncogenic viruses. ICGEB 2002. 